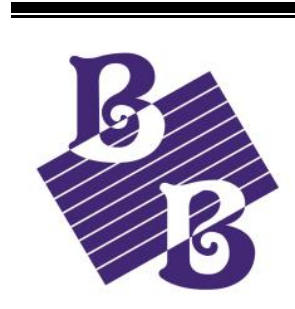

BioBacta

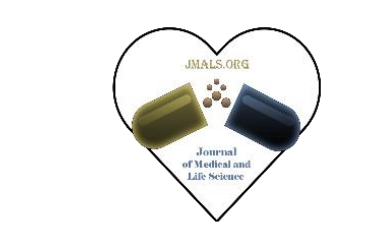

Journal of Medical and Life Science

www.jmals.org

\title{
Amelioration of the therapeutic efficacy of 5-Flurouracil loaded chitosan nanoparticles in experimentally induced Hepatocellular Carcinoma
}

\author{
EL-Hassan Mokhamer ${ }^{1}$, Mona M Yehia ${ }^{2}$, Heba S Ramadan ${ }^{3}$, and, Ola EL-Gendy ${ }^{4}$ \\ Zoology Department, Faculty of Science, Damanhour University ${ }^{1}$ \\ Histochemistry and Cell Biology Department, Medical Research Institute, Alexandria University ${ }^{2}$ \\ Medical Biophysicus Department, Medical Research Institute, Alexandria University ${ }^{3}$ \\ Applied Medical Chemistry Department, Medical Research Institute, Alexandria University 4 \\ (Email: elhassan,gaber@sci.dmu.edu.eg), Received Jan, 15, 2019; Accepted March,1,2019
}

Abstract

Hepatocellular carcinoma (HCC) is the most common type of liver cancer. The most important risk factor for the development of HCC is cirrhosis regardless of etiology. 5-Fluorouracil (5-FU) is widely used in the treatment of cancer. Drug resistance remains a significant limitation to the clinical use of 5-FU. The present study aimed to evaluate the therapeutic efficacy of 5-FU loaded chitosan nanoparticles in experimentally induced HCC. To achieve our purpose, one hundred and five male Swiss Albino mice were divided randomly into two major groups: Group A: comprised 25 mice served as normal control, Group B: comprised 80 mice received a daily oral dose of $0.06 \% \mathrm{DAB}$ (165 mg/kg body.wt.) for 30 days after which the water was replaced with $0.05 \%$ aqueous solution of Phenobarbital (PB). Five chosen mice randomly from groups A and $\mathrm{B}$ at the time intervals 15, 30, 45 and 60 days were sacrificed to follow up with the development of HCC by biochemical and histopathological examination. Animals of group B were divided into 3 groups Group I: included 20 mice served as an untreated group, group II: included 20 mice injected intraperitoneally with 5 -FU only (40mg/kg body.wt) every 2 days for 16 days, group III: included 20 mice injected intraperitoneally with 5-FU Cs NPs. Each group was further divided into two subgroups 10 mice each, one subgroup treated with ultrasonic waves; meanwhile the other subgroup without ultrasonic waves exposure. At the end of the experiment, animals were sacrified, serum ALT, hepatic ALT, and hepatic MDA were estimated; HCC was histopathologically monitored in all studied groups. There was 276.5\%, 145.7\%and 438.5\% increase in serum ALT, hepatic ALT and hepatic MDA levels respectively comparing to the corresponding control. Liver tumors that ultimately became neoplastic were produced after 45 days. US exposure triggered a significant decline in serum and hepatic ALT activity $(\mathrm{P}=$ 0.001) and in hepatic MDA ( $\mathrm{P}=0.009)$ within 5-FU loaded Cs NPs group. Moreover, tumor growth delay and more enhanced correction in hepatic architecture was obtained by a combination of US and 5-FU loaded Cs NPs therapy. Based on these results, we can conclude that the use of 5-FU loaded chitosan nanoparticles in combination with low-intensity ultrasound ameliorates the efficacy of 5-FU as anticancer therapy for HCC.

Keywords: Hepatocellular carcinoma, chitosan nanoparticles, 5-FU, Oxidative stress. 
1 Introduction

Hepatocellular carcinoma (HCC) is the fifth most common malignancy worldwide (El-Serag, 2002) and the third most common cause of cancer death. Despite advances in prevention techniques, screening, and new technologies in diagnosis and treatment, incidence and mortality continue to rise. The most important risk factor for the development of HCC is cirrhosis regardless of etiology. Hepatitis $\mathrm{B}$ and $\mathrm{C}$ are independent risk factors for the development of cirrhosis. (Balogh et al., 2016). Liver Transplantation offers the benefit of removal of cancer as well as the harboring risk of de novo HCC in a cirrhotic liver (Kulik et al., 2018). The disadvantages of most anti-cancer drugs that are currently available include low bioavailability, poor selectivity because they can act on both tumor cells and healthy cells, and immunosuppression that can cause complications and even patient death (Shah et al., 1985).

Continuous oxidative stress, which results from the generation of reactive oxygen species (ROS) by environmental factors or cellular mitochondrial dysfunction, has recently been associated with hepatocarcinogenesis. In liver disease, the infiltration of activated phagocytic cells provides an additional source of ROS production that promotes oxidative stress and damage to proteins, lipids, and DNA(Kaplowitz, 2000). ROS react with polyunsaturated fatty acids to induce the release of toxic and reactive aldehyde metabolites such as malondialdehyde (MDA) (Cheeseman, 1993, Saad et al., 2014). Malondialdehyde (MDA) is a marker for oxidative stress that is formed by lipid peroxidation and that was shown to accumulate in serum of chronic hepatitis patients(Nagoev et al., 2002).
5-Fluorouracil (5-FU) is widely used in the treatment of cancer. Over the past 20 years, an increased understanding of the mechanism of action of 5-FU has led to the development of strategies that increase its anticancer activity. Despite these advances, drug resistance remains a significant limitation to the clinical use of 5-FU. Modulation strategies, such as co-treatment with leucovorin and methotrexate, have been developed to increase the anticancer activity of 5-FU. (Longley et al., 2003). Chitosan, a natural cationic polysaccharide, is prepared industrially by the hydrolysis of the aminoacetyl groups of chitin, a naturally available marine polymer. Chitosan is a non-toxic, biocompatible and biodegradable polymer and has attracted considerable interest in a wide range of biomedical and pharmaceutical applications including drug delivery, cosmetics, and tissue engineering(Giri et al., 2012). Chitosan nanoparticles are a drug carrier with wide development potential and have the advantage of slow/controlled drug release, which improves drug solubility and stability, enhances efficacy, and reduces toxicity. Because of their small size, they are capable of passing through biological barriers in vivo (such as the blood-brain barrier) and delivering drugs to the lesion site to enhance efficacy(Shi and Fan, 2002).

A new method of drug targeting to a tumor is based on the localized release of drug at the tumor site by ultrasound focusing, the application of the external ultrasound to control drug delivery and to release from nanocarriers is a relatively novel approach. In the application ultrasound triggers the release of the drug from micelles as well as decomposing the membrane, thus enhancing the cellular uptake of both 
encapsulated and released drugs (Rapoport et al., 2003).

\section{Materials and Methods:}

\section{Chemicals:}

Chitosan (Cs) was obtained from Across Organics (Newgersey-USA). 5-flurouracil (5-FU), Sodium Tripolyphosphate (TPP) and Phenoparbital (PB) were purchased from Sigma Aldrich Chemie (GmbH-Germany), 4-dimethylaminoazobenzene (DAB) was purchased from Bio Basic (Canada Inc)., Acetic acid was purchased from (ADWIC, Egypt), Alanine Transaminase (ALT) kit from Diamond Diagnostics (Egypt) and MDA estimation kit from Biodiagnostic (Egypt).

\section{Methods}

\section{A: Preparation of nanoparticles (in vitro study)}

I. Preparation of hollow chitosan nanoparticles Chitosan has the ability to gel spontaneously on contact with multivalent polyanions due to the formation of inter- and intramolecular cross-linkage mediated by these polyanions. Among some polyanions investigated, tripolyphosphate (TPP) is the most commonly used because of its non-toxic property and quick gelling ability(Nagarwal et al., 2011, Aydin and Pulat, 2012)

Procedure:

Chitosan $0.2 \%(\mathrm{w} / \mathrm{v})$ solution was prepared in $1 \%$ (w/v) acetic acid aqueous solution. Tripolyphosphate was dissolved in deionized water at the concentration $0.07 \%(\mathrm{w} / \mathrm{v})$, then chitosan solution was flush mixed with an equal volume of TPP solution and the formation of chitosan-TPP nanoparticles started spontaneously via the TPP initiated ionic gelation mechanism. The $\mathrm{pH}$ of the final mixture was adjusted at 5.5 with $0.1 \mathrm{~N} \mathrm{NaOH}$. The nanoparticles were formed at selected chitosan to TPP weight ratio of 2.9:1(w/w). The nanoparticles suspensions were gently stirred for 60 minutes at room temperature using (Newtec.co magnetic stirrer MG model 2004). The mixture then was centrifuged for 60 minutes at $14,000 \mathrm{rpm}$ by cooling centrifugation at $4 \mathrm{C}^{\circ}$ (Hettich MIKRO 120 Centrifuge) and particles were separated and washed with deionized water then allowed for drying before being subjected to applications. Pellet was suspended in deionized water using ultrasonication (Branson ultrasonic cleaner B$22050 / 60 \mathrm{HZ}$ ) for $3 \mathrm{~min}$. The colloidal suspension was pre-frozen at $-80{ }^{\circ} \mathrm{C}$ for $24 \mathrm{~h}$. D-Trehalose $5 \%$ was added as a cryoprotectant to the colloidal suspension before the final freeze-drying. Nanoparticles were freeze-dried at $-50{ }^{\circ} \mathrm{C}$ for $12 \mathrm{~h}$ by lyophilization, and powder nanoparticles were used for further characterization (Nagarwal et al., 2011, Aydin and Pulat, 2012)

II. Preparation of 5-flurouracil loaded chitosan nanoparticles

Ideally, a successful nanoparticulate system should have a high drug-loading capacity thereby reduce the number of matrix materials for administration. Drug loading can be done by two methods: Incorporating at the time of nanoparticle production (incorporation method) or absorbing the drug after the formation of nanoparticles by incubating the carrier with a concentrated drug solution (adsorption /absorption technique). Drug loading and entrapment efficiency very much depend on the solid-state drug solubility in the matrix material or polymer (solid dissolution or dispersion), which is related to the polymer composition, the molecular weight, the drug-polymer interaction and the presence of end- functional groups (ester or carboxyl). For small molecules, studies show the use of ionic interaction between the drug and matrix materials can be a very effective way to increase drug loading (Mohanraj and Chen, 2006).

Procedure: 
5-FU loaded nanoparticles were obtained by the above-described procedure and the ratios of $\mathrm{Cs}$ and TPP remained unchanged. $(0.05 \mathrm{w} / \mathrm{v})$ of $5-\mathrm{FU}$ were incorporated in the Cs solution prior to the formation of nanoparticles in order to investigate the effect of the initial 5-FU concentration on the nanoparticle characteristics and in-vitro drug release. Also, supernatant was subjected to analysis for unloaded drug concentration by UV- Visible spectrophotometry at $265 \mathrm{~nm}$ (Mohanraj and Chen, 2006).

\section{B. Animals and induction of HCC.}

One hundred and five male Swiss Albino mice, three months old, weighing ( $25-40 \mathrm{~g})$ were used. the animals housed in stainless cages at the Animal House Unit at Medical Technology CenterUniversity of Alexandria under the following conditions; $12 \mathrm{hrs}$ dark/light cycle $22 \pm 2^{\circ} \mathrm{C}$ and $50 \pm 10 \%$ humidity. All animals received human care in compliance with the European Convention on Animal Care. Animals were handled according to the rules and regulations of the Institutional Animal Ethics Committee.

The animals were divided randomly into two major groups: Group A: 25 mice fed on a normal balanced diet and water ad libitum and served as normal controls. Group B: 80 mice fed the same diet as in the first group plus $0.06 \% \mathrm{DAB}$ at a daily dose of $165 \mathrm{mg} / \mathrm{kg}$ body.wt. per mouse administrated orally through a specially made fine pipette. (DAB was dissolved in paraffin oil) till 30 days after which the water was replaced with $0.05 \%$ aqueous solution of Phenoparbital till they were sacrified (Bhattacharjee et al., 2009a, Biswas et al., 2005).

Five chosen mice randomly from groups A and B at the time intervals $15,30,45$ and 60 days were sacrified to follow up the development of liver tumor HCC by histopathological examination.
After confirming the developing of the liver tumor by histopathological examination, animals of group B were left two weeks to induced chronic administrated animals termed chronic group divided into 3 groups as follow: Group I: 20 mice served as an untreated group. Group II: 20 mice injected intraperitoneally with 5-FU only (as free drug). (40mg/kg body weight) (Tominaga et al., 1993) was injected intraperitoneally every 2 days for 16 days ( $\mathrm{Li}$ et al., 2008) Group III: 20 mice injected intraperitoneally with 5-FU chitosan nanoparticles. On the same dose and schedule as group II. For group, I, intraperitoneal injections of the same volume of PBS were administered on the same schedule. Each group was further divided into two subgroups each of 10 mice, one group treated with ultrasonic waves, whereas the other subgroup received no treatment with ultrasonic waves. The mice were sacrificed on day $21^{\text {th }}$.

\section{C.Blood and tissue sampling:}

Blood samples were collected via ocular puncture from etherized mice, allowed for clotting at room temperature for about 30 minutes then serum was separated under centrifugation at $4000 \mathrm{rpm}$ at $4 \mathrm{C}^{\circ}$ and assayed at the same day.

Animals were sacrified, livers were quickly removed, washed with saline, bottled then each liver sample was weighed and divided into two parts. one part was kept in $10 \%$ formalin and processed for paraffin sections for histopathological studies. The second part was homogenized with cold $50 \mathrm{mM}$ phosphate buffer in (1:5) (w/v) at $\mathrm{pH} 7.4$, followed by centrifugation at $4000 \mathrm{rpm}$ for 15 minutes in a cooling centrifuge, the supernatant separated for MDA level and ALT activity on the same day.

\section{Biochemical investigations}


1. Serum Alanine aminotransferase activity (ALT)

The enzymatic activity of ALT in serum was estimated colorimetrically according to the method of Reitman and Frankel. Briefly, $0.5 \mathrm{ml}$ of the substrate (2 $\mathrm{mM} \alpha$-ketoglutarate, $0.2 \mathrm{M}$ L-alanine in $0.1 \mathrm{M}$ phosphate buffer $\mathrm{pH}$ 7.4) was incubated at $37^{\circ} \mathrm{C}$ for 5 minutes. $0.1 \mathrm{ml}$ of freshly prepared serum was added to the aliquot then incubated at $37 \mathrm{oC}$ for 30 minutes. At the end of incubation, $0.5 \mathrm{ml}$ of 2, 4-dinitrophenyl hydrazine was added, and the aliquot left for 30 minutes at room temperature. $0.5 \mathrm{ml}$ of $0.4 \mathrm{~N} \mathrm{NaOH}$ was added, and the aliquot was again left for 30 minutes. Absorbance was then recorded at $505 \mathrm{~nm}$ against water blank (Reitman and Frankel, 1957).

\section{Hepatic Alanine aminotransferase activity} (ALT)

The enzymatic activity of ALT in tissue homogenate was estimated colorimetrically according to the method of Reitman and Frankel. (Reitman and Frankel, 1957).

\section{Hepatic Malondialdehyde level (MDA)}

The hepatic MDA was estimated according to the method of Ottolenghi. The formation of malonaldehyde is the basis for the well-known thiobarbituric acid (TBA) method used for evaluating the extent of lipid peroxidation. At low $\mathrm{pH}$ and high temperature $\left(100^{\circ} \mathrm{C}\right)$, MDA binds TBA to form a red complex that can be measured at $534 \mathrm{~nm}$ (Ottolenghi, 1959).

\section{E. Histopathological examination of liver}

Part of the liver was kept in $10 \%$ formalin and processed for paraffin sections. Paraffin sections were mounted on clean slides, placed at $37^{\circ} \mathrm{C}$ oven. Sections were deparaffinized in xylene, rehydrated in descending grades of alcohol to distilled water, stained with Hematoxylin, washed in tap water then stained with Eosin, dehydrated in ascending grades of alcohol and cleared in xylene. Coverslip applied by Canada balsam and examined under a light microscope(Drury and Wallington, 1980).

\section{F. Statistical analysis}

The statistical analysis was computed using the Mann - Whitney test. $\mathrm{P}$ values $\leq 0.05$ were considered statistically significant.

\section{Results}

\section{A. Biochemical results during $\mathrm{HCC}$ induction 1. Serum ALT activity}

Feeding of DAB and PB caused a significant increase in serum ALT activities through the different intervals when compared to their corresponding control animals, Figure (1).

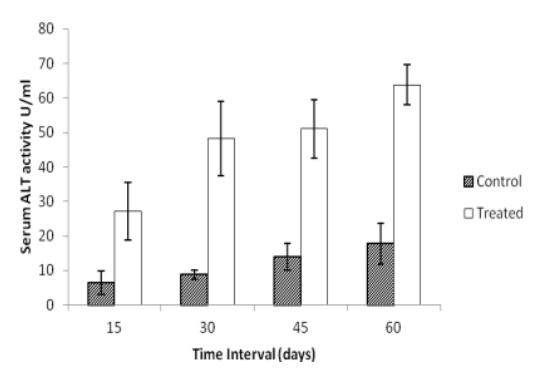

Figure (1): Serum ALT activity (U/ml)( Mean \pm S.D)

\section{Hepatic ALT activity:}

The same trend as serum ALT activity, hepatic ALT levels were noticeably increased under the effect of $\mathrm{DAB}$ and $\mathrm{PB}$ feeding when compared to their corresponding control animals at all intervals Figure (2).

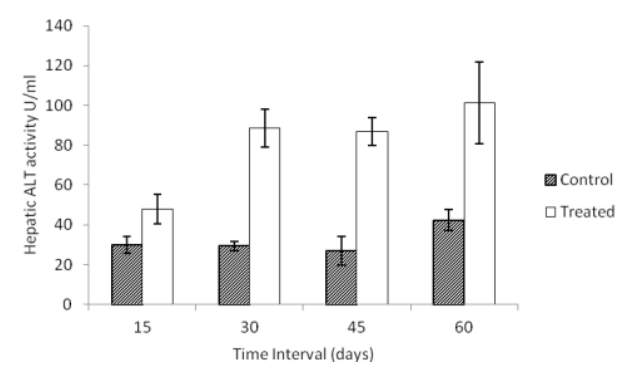

Figure (2): Hepatic ALT activity (U/ml) (Mean \pm S.D) 


\section{Hepatic MDA level:}

Hepatic MDA level was significantly increased in $\mathrm{DAB}$ and $\mathrm{PB}$ fed mice at all intervals when compared with the corresponding control animals, Figure (3).

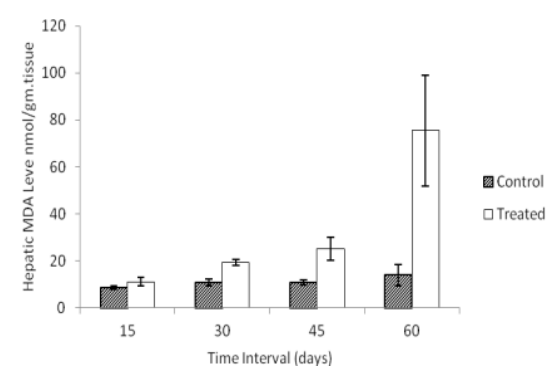

Figure (3): Hepatic MDA level (nmol/g. tissue) (Mean \pm S.D)

\section{B. Biochemical results after the induction of HCC}

1. Serum ALT activity
Mice treated with free 5-FU (group II) showed no significant difference when compared to mice bearing the liver nodules in group $\mathrm{I}(\mathrm{p} 1=0.217)$ while treating mice with 5-FU loaded Cs NPs caused a highly significant decrease in ALT level when compared to group I $(\mathrm{p} 1=0.004 *)$. A significant decrease in ALT level was obtained when comparing mice received 5-FU loaded Cs NPs (group III) with those received free 5-FU (group II) $(\mathrm{p} 1=0.030 *)$. On the other hand, exposing mice to the US caused a significant decrease in ALT level when comparing both groups II and III to a group I being more significantly decreased in group III (p2 $=0.014 *$, $0.001 *$ and $<0.001 *$ ) respectively. Within the same group, the US triggered a significant decline in ALT level only in group III ( $\mathrm{p}=0.001)$, Table (1)

Table (1): Serum ALT level (U/ml) in different treated groups.

\begin{tabular}{|c|c|c|c|c|c|c|}
\hline & \multirow{2}{*}{\multicolumn{2}{|c|}{$\begin{array}{c}\text { DAB }+ \text { PB feeding group } \\
\text { Group I }\end{array}$}} & \multicolumn{4}{|c|}{ Treated Groups } \\
\hline & & & \multicolumn{2}{|c|}{$\begin{array}{c}\text { 5-FU } \\
\text { Group II }\end{array}$} & \multicolumn{2}{|c|}{$\begin{array}{c}\text { 5-FU loaded Cs Nanoparticles } \\
\text { Group III }\end{array}$} \\
\hline & Without US & With US & Without US & With US & Without US & With US \\
\hline $\mathrm{n}$ & 10 & 10 & 10 & 10 & 10 & 10 \\
\hline Range & $53.0-75.0$ & $48.0-70.0$ & $36.0-72.0$ & $38.0-52.0$ & $30.0-60.0$ & $13.80-39.10$ \\
\hline $\begin{array}{l}\text { Mean } \\
\pm \text { SD }\end{array}$ & $63.80 \pm 8.70$ & $57.20 \pm 8.44$ & $\begin{array}{l}54.40 \pm \\
12.76\end{array}$ & $44.38 \pm 5.85$ & $41.80 \pm 10.32$ & $26.58 \pm 9.48$ \\
\hline Median & 61.00 & 56.00 & 55.00 & 42.0 & 40.00 & 22.60 \\
\hline $\mathrm{P}$ & & 0.172 & & 0.095 & & $0.001^{*}$ \\
\hline $\mathrm{P} 1$ & & & 0.217 & & & \\
\hline $\mathrm{P} 2$ & & & & $0.014^{*}$ & & \\
\hline $\mathrm{P} 1$ & & & & & $0.004^{*}$ & \\
\hline $\mathrm{P} 2$ & & & & & & $0.001^{*}$ \\
\hline $\mathrm{P} 1$ & & & & & $0.030^{*}$ & \\
\hline P2 & & & & & & $<0.001^{*}$ \\
\hline
\end{tabular}

$\mathrm{P}$ : P value for Mann Whitney test between with and without ultrasound in each group

P1: P value for Mann Whitney test between treated and each other treated group without US

P2: P value for Mann Whitney test between treated and each other treated group with US

*: statistically significant at $\mathrm{P} \leq 0.05$ 


\section{Hepatic ALT activity}

Mice treated with free 5-FU (group II) showed a significant decrease when compared to mice bearing the liver nodules in group I $\left(\mathrm{p} 1=0.035^{*}\right)$, while treating mice with 5-FU loaded Cs NPs caused a highly significant decrease in ALT level when compared to group I $(\mathrm{p} 1=0.001 *)$. Besides, a significant decrease in ALT level was obtained when comparing mice received 5-FU loaded Cs NPs (group III) with those received free 5-FU (group II)
( $\mathrm{p} 1<0.001 *)$. On the other hand, exposing mice to the US caused no significant decrease in ALT level when comparing group II to group I ( $22=0.459)$, while US exposure significantly decreased ALT level of group III when comparing to a group I and II (p2 = $0.001 *, \mathrm{p} 2=<0.001 *)$ respectively. Within the same group, the US triggered a significant decline in ALT level in group II \&III $(\mathrm{p}=.048 *, \mathrm{p}=0.001 *)$ respectively, Table (2).

Table (2): Hepatic ALT level (U/ml) in different treated groups.

\begin{tabular}{|c|c|c|c|c|c|c|}
\hline & \multirow{2}{*}{\multicolumn{2}{|c|}{$\begin{array}{l}\mathrm{DAB}+\text { PB feeding group } \\
\text { Group I }\end{array}$}} & \multicolumn{4}{|c|}{ Treated Groups } \\
\hline & & & \multicolumn{2}{|c|}{$\begin{array}{c}\text { 5-FU } \\
\text { Group II }\end{array}$} & \multicolumn{2}{|c|}{$\begin{array}{l}\text { 5-FU loaded Cs Nanoparticles } \\
\text { Group III }\end{array}$} \\
\hline & Without US & With US & Without US & With US & Without US & With US \\
\hline $\mathrm{n}$ & 10 & 10 & 10 & 10 & 10 & 10 \\
\hline Range & $84.00-111.00$ & $69.00-102.00$ & $76.00-93.00$ & $72.00-90.00$ & $35.80-71.10$ & $35.00-52.00$ \\
\hline Mean \pm SD & $100.20 \pm 10.08$ & $86.40 \pm 14.67$ & $85.12 \pm 5.72$ & $79.80 \pm 6.55$ & $56.80 \pm 13.24$ & $40.40 \pm 6.95$ \\
\hline Median & 102.00 & 86.00 & 85.00 & 80.00 & 57.20 & 36.00 \\
\hline $\mathrm{P}$ & & 0.142 & & $0.048^{*}$ & & $0.001^{*}$ \\
\hline $\mathrm{P} 1$ & & & $0.035^{\star}$ & & & \\
\hline P2 & & & & 0.459 & & \\
\hline $\mathrm{P} 1$ & & & & & $0.001^{*}$ & \\
\hline $\mathrm{P} 2$ & & & & & & $0.001^{*}$ \\
\hline $\mathrm{P} 1$ & & & & & $<0.001^{*}$ & \\
\hline $\mathrm{P} 2$ & & & & & & $<0.001^{*}$ \\
\hline
\end{tabular}

$\mathrm{P}$ : P value for Mann Whitney test between with and without ultrasound in each group

P1: P value for Mann Whitney test between treated and each other treated group without US

P2 : P value for Mann Whitney test between treated and each other treated group with US

*: statistically significant at $\mathrm{P} \leq 0.05$

\subsubsection{Hepatic MDA level}

Mice treated with free 5-FU (group II) showed no significant difference when compared to mice bearing the liver nodules in group I $(\mathrm{p} 1=0.064)$, while treating mice with 5-FU loaded Cs NPs caused a significant decrease in MDA level when compared to group I $(\mathrm{p} 1=0.002 *)$. A significant decrease in MDA level was obtained when comparing mice received 5FU loaded Cs NPs (group III) with those received free 5-FU (group II) $(\mathrm{p} 1<0.001 *)$.
On the other hand, exposing mice to the US caused a significant decrease in MDA level when comparing both groups II and III to a group I being more significantly decreased in group III (p2 $=0.004 *$, $0.002 *$ and $<0.001 *$ ) respectively. Within the same group, the US triggered a significant decline in the MDA level in groups II \& III ( $\left.\mathrm{p}=0.010^{*}, 0.009^{*}\right)$ respectively, Table (3). 
Table (3): Hepatic MDA level (nmol/g.tissue) in different treated groups.

\begin{tabular}{|c|c|c|c|c|c|c|}
\hline & \multirow{2}{*}{\multicolumn{2}{|c|}{$\begin{array}{l}\mathrm{DAB}+\mathrm{PB} \text { feeding group } \\
\text { Group I }\end{array}$}} & \multicolumn{4}{|c|}{ Treated Groups } \\
\hline & & & \multicolumn{2}{|c|}{$\begin{array}{c}5-\mathrm{FU} \\
\text { Group II }\end{array}$} & \multicolumn{2}{|c|}{$\begin{array}{l}\text { 5-FU loaded Cs Nanoparticles } \\
\text { Group III }\end{array}$} \\
\hline & Without US & With US & Without US & With US & Without US & With US \\
\hline $\mathrm{n}$ & 10 & 10 & 10 & 10 & 10 & 10 \\
\hline Range & $84.00-105.00$ & $82.00-109.00$ & $70.00-99.00$ & $44.00-79.00$ & $10.19-41.20$ & $9.60-33.50$ \\
\hline Mean \pm SD & $95.50 \pm 9.33$ & $95.75 \pm 11.50$ & $83.22 \pm 12.40$ & $60.40 \pm 15.18$ & $28.75 \pm 9.68$ & $19.42 \pm 8.96$ \\
\hline Median & 98.50 & 96.00 & 84.00 & 62.00 & 29.69 & 15.60 \\
\hline$P$ & & 0.773 & & $0.010^{*}$ & & $0.009^{*}$ \\
\hline $\mathrm{P} 1$ & & & $0.064^{*}$ & & & \\
\hline $\mathrm{P} 2$ & & & & $0.004^{*}$ & & \\
\hline P1 & & & & & $0.002^{*}$ & \\
\hline $\mathrm{P} 2$ & & & & & & $0.002^{*}$ \\
\hline $\mathrm{P} 1$ & & & & & $<0.001^{*}$ & \\
\hline $\mathrm{P} 2$ & & & & & & $<0.001^{*}$ \\
\hline
\end{tabular}

$\mathrm{P}: \mathrm{P}$ value for Mann Whitney test between with and without ultrasound in each group

P1: P value for Mann Whitney test between treated and each other treated group without US

P2 :P value for Mann Whitney test between treated and each other treated group with US

*: statistically significant at $\mathrm{P} \leq 0.05$

\section{Histopathological results during $\mathrm{HCC}$}

\section{induction}

Paraffin sections of mice liver in all animal groups were stained by $\mathrm{H} \& \mathrm{E}$ to study the histopathological changes under light microscopy.

\section{Control group:-}

Normal control (group A) liver sections architecture characterized as liver tissue with the central vein, normal hepatocytes distributed among a few numbers of eosinophilic cells and mild dilation of the portal tract (Fig.4).

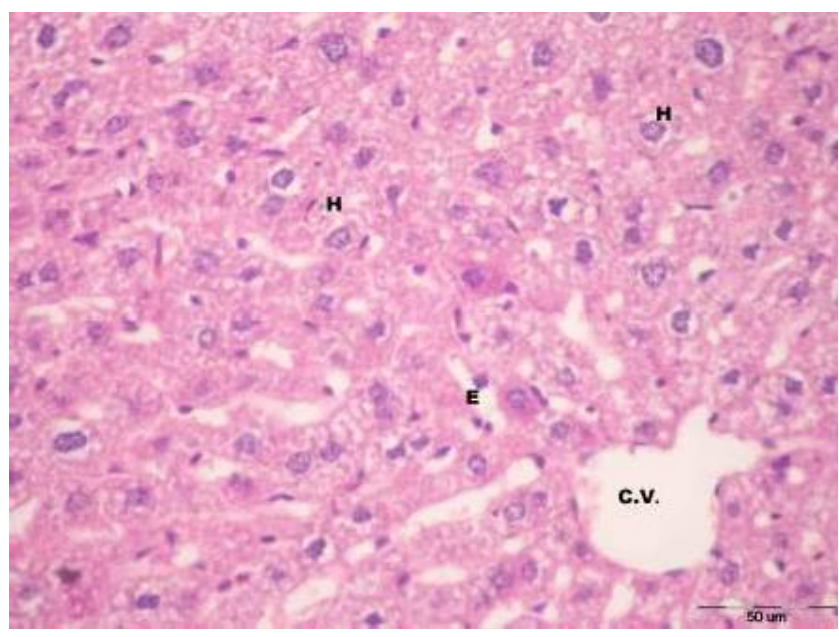

Figure (4): Paraffin section photograph of control three months old mice liver showing normal central vein (C.V.), normal hepatocytes $(\mathrm{H})$ distributed among small number of eosinophilic 
Liver section of the experimental control group (DAB and PB feeding group) (group B): At a different intervals of feeding $\mathrm{DAB}$ and $\mathrm{PB}$, the liver showed mild histological changes on day 15. After 30 days, the sections had large

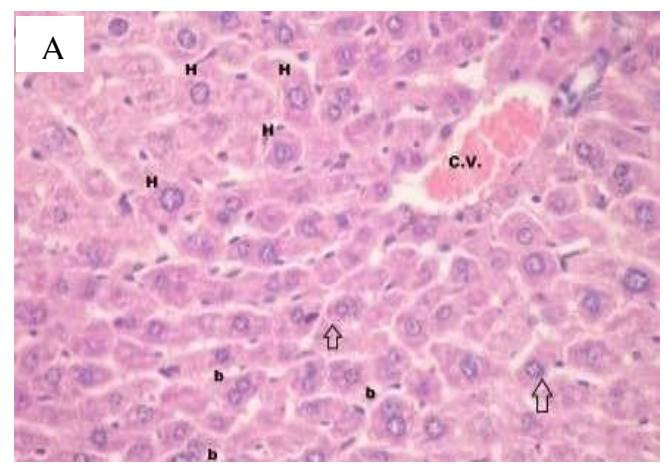

hepatocytes with eosinophilic cytoplasm, congested central vein and there was an increase in a number of binucleated cytoplasms (Fig.5A), follicular nodules of infiltrated lymphocytic cells with an increasing number of kupffer cells in dilated sinusoids ( Fig. 5B).

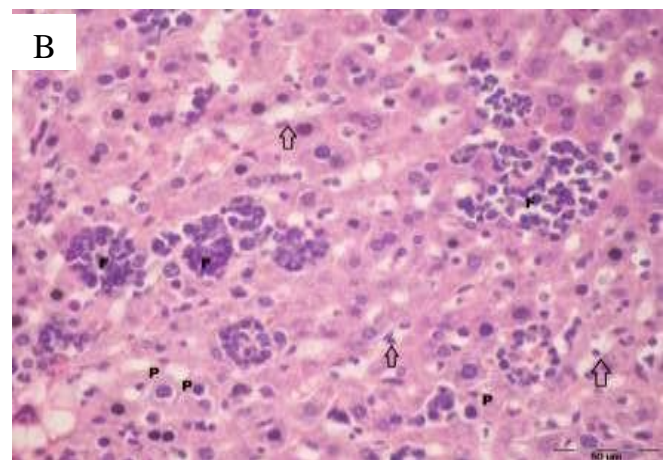

Figure (5): Paraffin section photograph of mice liver at 30 day of DAB and PB feeding. (A): showing congested central vein (C.V.), large hepatocytes $(\mathrm{H})$ with eosinophilic cytoplasm, increase number of binucleated hepatocytes (b), visculated nuclei of hepatocytes with basophilic cytoplasm was noticed( $(\mathbb{U})$. (B): showing follicular nodules of infiltrated lymphocytic cells (F), Small Hepatocytes with pyknotic nuclei are found $(\mathrm{P})$, increasing number of kupffer cells in dilated sinusoids (仓).

The histopathological changes of liver tissue at 30 days of $\mathrm{DAB}$ and $\mathrm{PB}$ indicated that the carcinogen-induced tumors in a large areas of liver tissue. At day 45, the sections had angiogenesis formation, aggregation of cells with hyperchromatic nuclei and appearance of

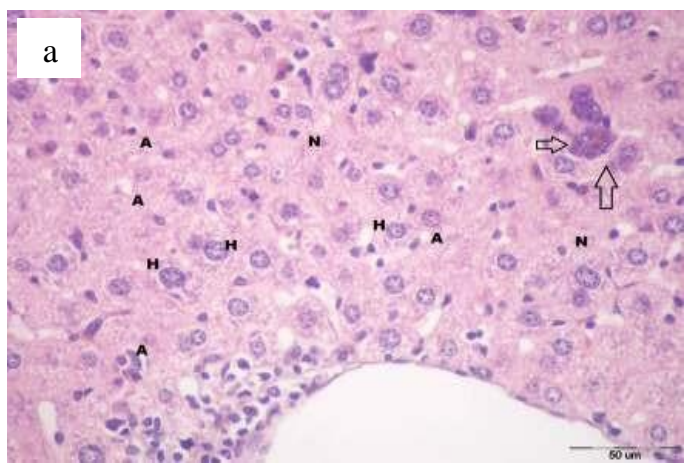

some necrotic cells (Fig.6a). The continuous feeding of DAB and PB through 60 days caused a loss of the architecture of liver lobules with an increasing number of apoptotic cells, pyknotic hepatocytes with vacuolated cytoplasm and areas of karyolitic cells (Fig.6b).

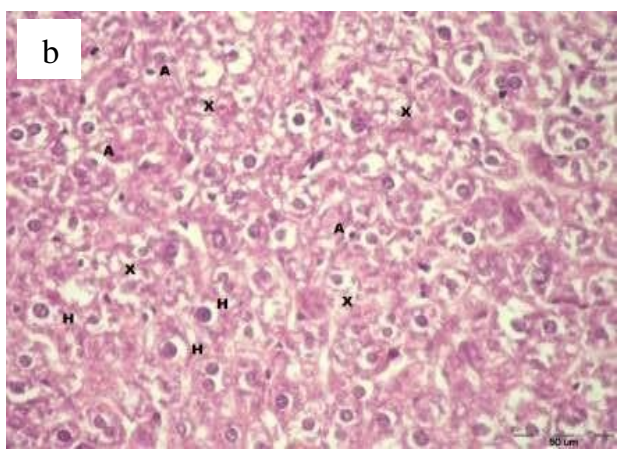

Figure (6): Paraffin section photograph of mice liver.(a): at 45 day of DAB and PB feeding showing area of multinucleated cells( () , new angiogenesis formed (A), some necrotic cells $(\mathrm{N})$ and hyperchromated hepatocytes $(\mathrm{H})$, increase in kupffer cells number.(b): after 60 days of DAB and PB feeding showing pyknotic hepatocytes with vacuolated cytoplasm $(\mathrm{H})$, increasing number of apoptotic cells $(\mathrm{A})$, and area of karyolitic cells $(\mathrm{X})$. 


\section{Histopathological results due to the different therapeutic effects on HCC DAB and PB feeding group (group I)}

The liver sections of the untreated group lost its architecture with the appearance of giant cells with large nuclei and central vein congestion (Fig.4a).
While the sections exposed to the ultrasonic waves (US) showed little follicular nodules of infiltrated lymphocytic cells with angiogenesis and appearance of regenerative hepatocytes, i.e. a mild recovery caused by the effect of ultrasonic exposure (Fig.7.b).
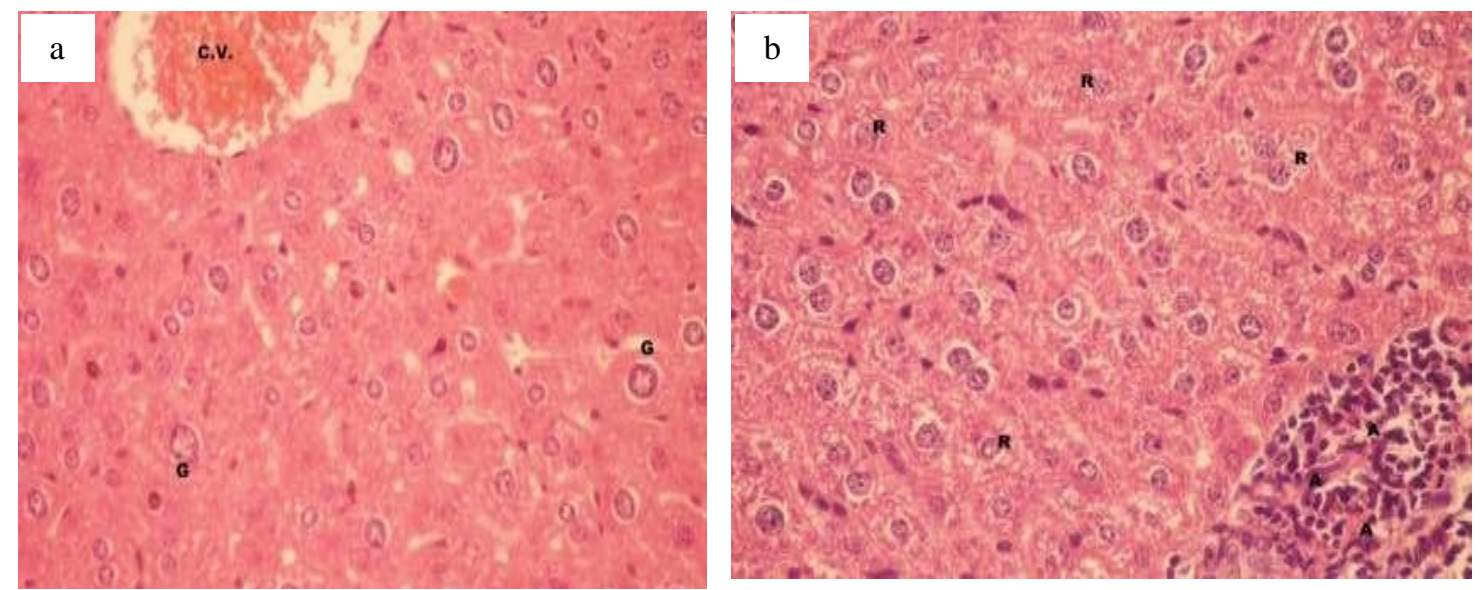

Figure (7). (a): Paraffin section photograph of mice liver of chronic DAB and PB feeding group of mice without US exposure. (b): mice exposed to US (H\&E, Bar $=50 \mu \mathrm{m})$

\section{Free 5-FU treated group (group II):}

After the administration of free 5-FU intraperitoneal injection, the sections had proliferation in the wall of the artery and bile duct, with an increasing number of proliferating lymphocytic cells and a decreased number of apoptotic cells, Figure (8.a). On the other hand, liver sections of this group exposed to the US showed some recovery in liver tissue characterized by proliferating lymphocytes around the bile duct, dilation and congestion of the portal tract, increased number of kupffer cells and regenerative hepatocytes, Figure (8.b).

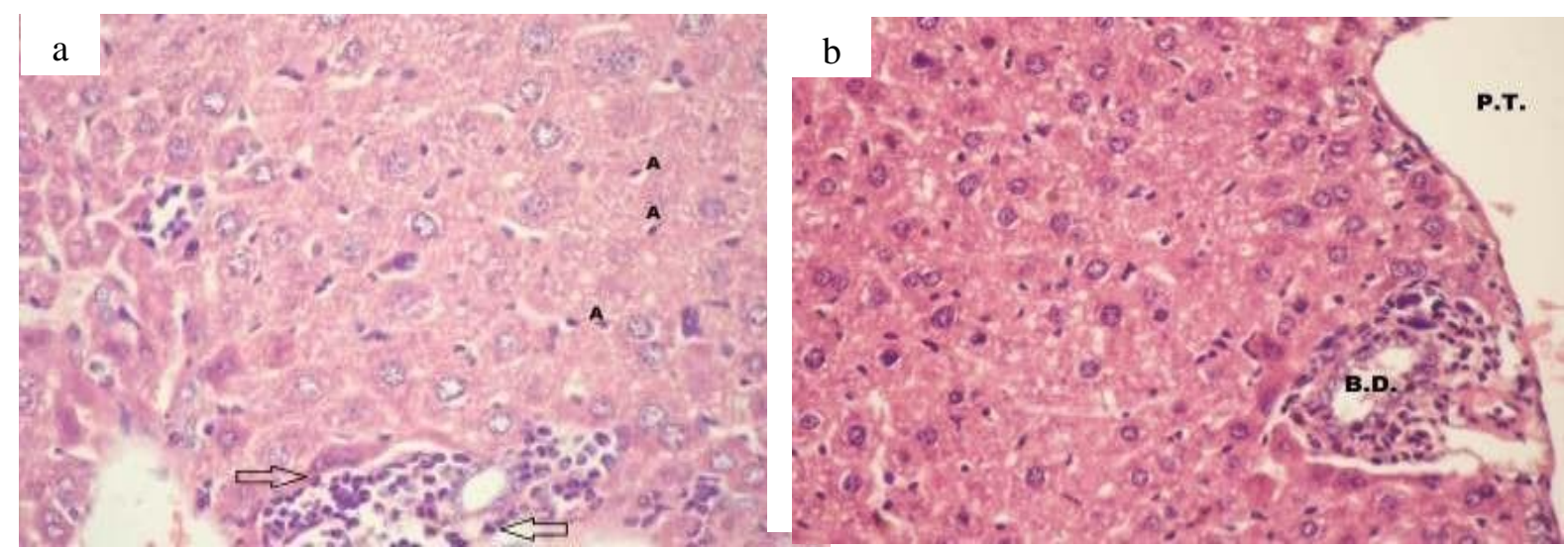

Figure (8): (a).Paraffin section photograph of mice liver of group received 5-FU injection showing increase in number of proliferating lymphocytic cells in sinusoids and histocytes ( $)$, decreased number of apoptotic cells (A) and proliferation in the wall of the artery and bile duct.(b). mice liver of group received 5-FU + US exposure showing proliferating lymphocytes around dilated bile duct (B.D.) and congested portal tract (P.T.), increased number of hepatocytes with visculated nuclei and eosinophilic cytoplasm, increase in number of kupffer cells, some regenerative hepatocytes. (H\&E, Bar $=50 \mu \mathrm{m})$ 


\section{5-FU loaded Cs nanoparticles treated group (group III) :}

The liver sections of this group of mice received 5-FU loaded Cs nanoparticles injection showed partial restoring of the architecture of hepatic lobules with the appearance of hyaline in dilated sinusoids matrix (as a results of the presence of glycosyle debris induced due to the degradation of the
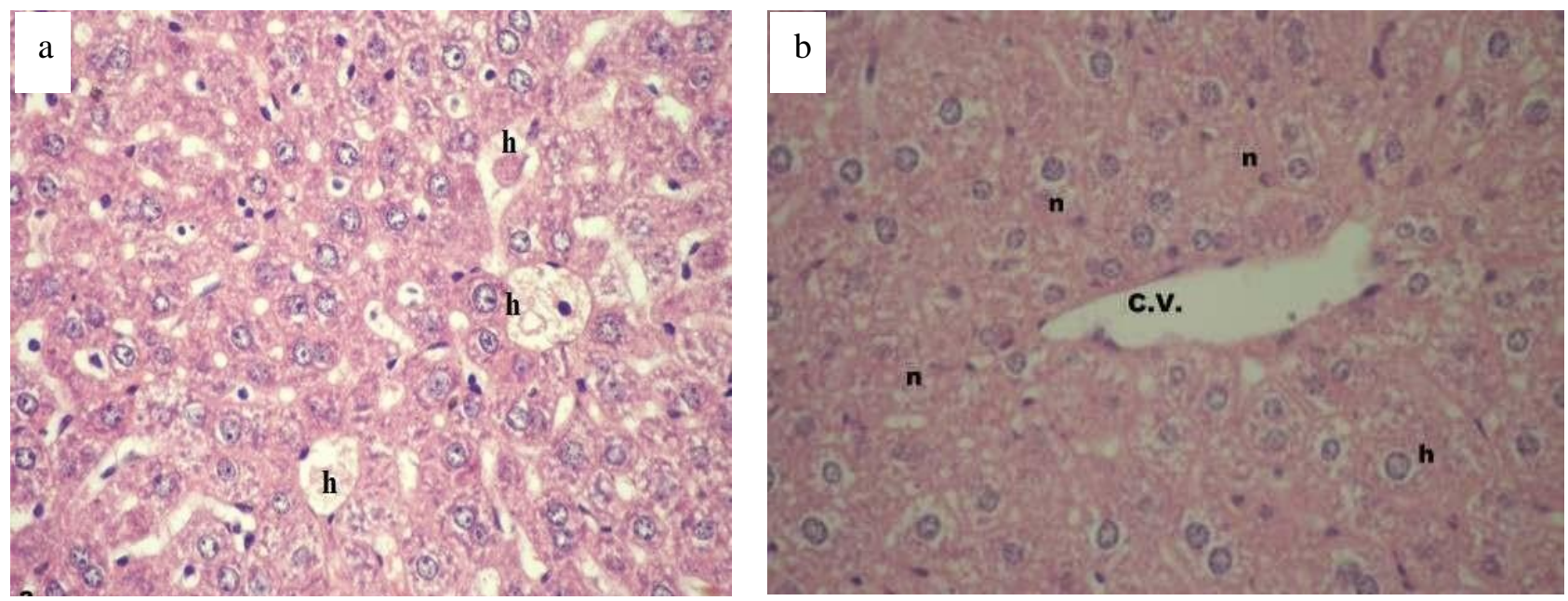

polysaccharide matrix in sinusoids during digestion), Figure (9.a) with increasing number of regenerative hepatocytes and kupffer cells Figure. Also, this group exposed to the US after the 5-FU loaded Cs nanoparticle injections showed newly formed hepatocyte and other hepatocytes with large vesculated nucleus, slightly dilated central vein and few apoptotic cells, Figure (9.b).

Fig(9) : (a). Paraffin section photograph of mice liver of group received 5-FU loaded Cs nanoparticles showing dilation of sinusoids with hyaline matrix (h), the ratio of nucleus to cytoplasm is $1: 2$, increased number of kupffer cells.(b). mice liver of group received 5-FU loaded Cs nanoparticles and US exposure showing newly formed hepatocytes (n) and others with large visculated nuclei (h). (H\&E, Bar $=50 \mu \mathrm{m})$

\section{Discussion}

Carcinogenesis typically involves multiple steps. An initiating step that mutates DNA of the cell, the promotional stage that may involve evasion of apoptosis and uninhibited cell growth in the presence of endogenous or exogenous growth factors. As the neoplasm proceeds, the cells acquire self-sufficiency in growth and overcome inhibitory signals and immune surveillance, followed by angiogenesis and invasion of host tissue (De Minicis et al., 2013, Filler et al., 2007, Hanahan and Weinberg, 2000, Basu, 2018).

Owing to the physiologic and genetic similarities between rodents and humans, the laboratory mouse is 
(Bakiri and Wagner, 2013). Based on this knowledge, in the present study, we experimentally induced $\mathrm{HCC}$ in male adult mice using $0.06 \% \mathrm{DAB}$ solution (initiator) at a daily dose of $165 \mathrm{mg} / \mathrm{kg}$ body wt. per mouse, administrated orally till 30 days after which the water was replaced with $0.05 \%$ aqueous solution of phenobarbital (promoter) till they were sacrified.

The elevation value of serum ALT has been widely used as a sensitive parameter for the assessment of liver injury degree (Kwo et al., 2017). However, its value does not correctly reflect the degree of hepatic cell necrosis. Although injured cells have an increase in its membrane permeability with an elevation in serum ALT, its elevation is not parallel to the degree of damage. Many factors as etiology of the liver disease or the severity of the liver cell necrosis can affect the mechanism of elevation (Woreta and Alqahtani, 2014)

In the present study, the results showed a decrease in body weight in DAB and PB fed group compared to the control one. These results were in agreement with Bhattacharjee et al, who found weight loss in disturbed liver proliferation activity (Bhattacharjee and Khuda-Bukhsh, 2015) DAB and PB feeding significantly increased serum and hepatic ALT activities through the different intervals when compared to their corresponding control animals. At 60 days of $\mathrm{DAB}$ and $\mathrm{PB}$ feeding, there was $276.5 \%$ \& $145.7 \%$ increase in serum and hepatic ALT activity respectively comparing to the corresponding control. This result was in agreement with Pathak $S$ et al, who manifested that $\mathrm{DAB}$ and $\mathrm{PB}$ intoxication significantly raised serum AST \& ALT levels(Pathak et al., 2009).
Several carcinogens are known to be pro-oxidant that contribute to the induction of oxidative stress and hence carcinogenesis in experimental animal models (Saha et al., 2017). Oxidative stress can affect DNA via oxidation of purine and pyrimidine bases, strand breaks and microsatellite instability. Its effect on protein lead to alteration in its function while on lipids it enhances lipid peroxidative events producing MDA(Forouzandeh et al., 2017).

MDA, the end-product of lipid peroxidation, previously has been reported chronic hepatitis $\mathrm{C}$ (CHC) patients have increased serum and hepatic MDA levels (Khan and Ali, 2018). Li et al, reported that the MDA level in CHC patients was statistically significantly higher when compared to the healthy control group(Li et al., 2015). In the present study, the MDA level was significantly increased in the DAB and PB feeding group of mice at all intervals when compared with the corresponding control animals. At 60 days of DAB and PB feeding, there was a $438.5 \%$ increase in hepatic MDA level comparing to the corresponding control. These results were in agreement with (Bhattacharjee et al., 2009b), they found pronounced elevation of MDA in the DAB treated group of mice accompanied with lowering levels of antioxidant enzymes (Pathak et al., 2018)

In addition, chronic intake of $\mathrm{DAB}$ and $\mathrm{PB}$ is known to induce a plethora of cytotoxic and genotoxic alterations (Biswas et al., 2008). It was demonstrated that feeding of carcinogenic azo dyes produced liver damage followed by regeneration of parenchymal cells, a proliferation of bile ducts and connective tissue, and at later stages tumors developed from liver parenchyma that ended up with neoplastic characteristics (Bhattacharjee et al., 2009b). In the present study, at day 15 after DAB and PB feeding, 
mice liver showed follicular nodules of infiltrated lymphocytic cells with an increasing number of kupffer cells in dilated sinusoids. Moreover, at 30 and 45 days aggressive histological changes such as angiogenesis formation were observed, aggregation of cells with hyperchromatic nuclei and appearance of some necrotic cells under the cumulative effect of $\mathrm{DAB}$ and $\mathrm{PB}$ feeding. In addition, pyknotic hepatocytes with vacuolated cytoplasm and areas of karyolitic cells were shown after 60 days. The current result was in agreement with the result of Biswas SJ et al(Biswas and Khuda-Bukhsh, 2002), who demonstrated that dietary $\mathrm{PB}$ with the azo dye had positive carcinogenic effect, but neither of these two when fed alone showed positive hepatocarcinogenesis in both mice and rat(Bhattacharjee and Khuda-Bukhsh, 2012). In our study, liver tissue injury began after 15 days and the continuous feeding of $\mathrm{DAB}$ and $\mathrm{PB}$ caused tumor lesion to appear after 30 days. Therefore, the cumulative feeding of $\mathrm{DAB}$ and $\mathrm{PB}$ promotes the carcinogenic event, as a toxic effect of DAB was introduced through the 60 days feeding and the addition of PB promoted the cytotoxic effect of DAB and caused weight loss in mice with disturbed liver proliferation activity and liver tumor. The feeding DAB combined with $\mathrm{PB}$ produces liver tumors that ultimately became neoplastic after 45 days.

A relatively novel strategy for gene and drug delivery enhancement is the application of nanoparticles in combination with relatively low-intensity ultrasound (US). This method (referred to as "sonoporation") can induce cavitations of or near cellular membranes to enhance the delivery of drugs in vitro and in vivo. In general, beneficial and reversible cellular effects can be induced by the low-intensity US, in contrast to high US intensities, which are more likely to induce cellular death. Sonoporation is an emerging and promising physical method for drug and gene delivery enhancement in vitro and in vivo (Larina et al., 2005, Zolochevska et al., 2011).

Ultrasound can be used in combination with chemotherapy agents for several reasons. It has been shown to enhance the transport of drugs and other chemicals into cells and tissues. The cytotoxic efficiency of chemotherapeutic agents has been shown to increase under the action of ultrasound. Since ultrasound increases the local temperature of the exposed tissues, hyperthermia can be used as an additional ultrasonic advantage (Figueiredo and Esenaliev, 2012)

The mechanism of sonoporation involves the motion and disruption of nanoparticles induced by lowintensity US sonication.US increase the permeability of cell membranes and the endothelium, thus enhancing therapeutic uptake, and can locally increase drug transport. Sonoporation mediates delivery of drugs that have been incorporated into or on the surface of nanoparticles via covalent or electrostatic interactions, which allow these complexes to circulate in the blood and retain their cargo until activation by the US. US application results in localized and spatially controlled particle disruption that enhances drug delivery. Sonoporation does not appear to negatively impact cellular viability of insonated tumor cells or normal surrounding tissues after treatment with either chemotherapeutic drugs or plasmid DNA in vitro or in vivo (Horsley et al., 2019, Larina et al., 2005)

Specific targeting of tumor cells to achieve higher drug levels in tumor tissue and to overcome the side effects is the major goal in cancer therapy. Therefore, in the present study, we investigated the therapeutic efficacy of the formulated 5-FU Cs NPs in the 
treatment of the experimentally induced $\mathrm{HCC}$ in mice as compared to the impact of the conventional 5-FU free drug injection under the absence/presence of ultrasonic exposure.

The biochemical results showed mild recovery of the liver tissue in groups treated with the free form of 5FU with no significant difference in serum ALT activity $(0.1 \%$ decrease $)$ when compared to mice bearing the liver nodules, slight decrease in hepatic ALT activity $(0.16 \%$ decrease $)\left(P=0.035^{*}\right)$ and no significant difference in hepatic MDA level when compared to mice bearing the liver nodules. These results were in accordance with Abdel-Hamid et al. who showed that transaminase activities were reduced after 5-FU treatment (Abdel-Hamid et al., 2011). The persistent increase in the MDA level may be due to resistance to the 5- FU treatment as a cellular adaptive response to ROS is a mechanism of drug resistance to 5- FU. While acute oxidative stress triggers cell apoptosis or necrosis, persistent oxidative stress induces genomic instability and has been implicated in tumor progression and drug resistance. It was shown that tumor cells that adapt to oxidative stress by increasing manganese superoxide dismutase (MnSOD), Prx I and Bcl-2, show drug resistance to 5- FU(Hwang et al., 2007).

The improvement in the histological features of the liver after treatment with 5-FU injection was supported by the same result of Abdel Hamid et al, who found that 5- FU corrected the histological changes after carcinogen administration except that some necrotic and cytotoxic effects of 5-FU were still shown (Abdel-Hamid and Morsy, 2010). Animals treated with free 5- FU with ultrasonic exposure showed moderate histological changes, increase in the number of kupffer cells with the appearance of proliferating lymphocytes, these results described the bioeffect of ultrasound which initiate a resistant immune response toward the conventional 5-FU treatment

The therapy of 5-FU can be improved and its toxicity diminished by facilitating the specific accumulation of this anticancer agent in the tumor under US exposure. In addition, the association of anticancer drugs to delivery systems has been an interesting approach to selectively delivering these active agents and reducing their toxicity. In the present work, animals treated with 5-FU loaded chitosan nanoparticles showed improvement of liver tissues as restoring of the architecture of hepatic lobules with the appearance of a hyaline matrix in dilated sinusoids, increasing number of regenerative hepatocytes and kupffer cells. These findings were confirmed by the biochemical results of ALT activity and MDA level, which demonstrated a significant decrease in serum and hepatic ALT activity in the group that received 5-FU loaded chitosan nanoparticles when compared with the group received free 5-FU injection $\left(\mathrm{p}=0.030^{*}\right)$ and $(\mathrm{p}<$ $0.001 *)$ respectively. This is in agreement with Cheng et al. who found that the levels of AST and ALT in 5-FU loaded glycocylated chitosan NPs group were lower compared with 5-FU group (Cheng et al., 2012), Also, high significant decrease in hepatic MDA levels was obtained when compared that of mice received 5- FU loaded Cs NPs with those received free 5-FU $\left(\mathrm{P}<0.001^{*}\right)$.

These present findings introduced the role of the nanoparticles for carrying drugs, adding a new concept for the drug delivery in carrying the chemotherapy as it is available and easy. This is consistent with previous reports where good antitumor activity of 5-FU- loaded N-succinyl chitosan nanoparticles was observed against Sarcoma 
180 solid tumor with mild toxicity (Yan et al., 2006), conjugation of glycocylated chitosan to 5-FU improved the tumor-suppressive effect and the apoptotic effect of 5-FU in hepatic cancer cells, the mechanism of 5-FU loaded chitosan nanoparticles action in tumor inhibition resulted from induction of G0-G1 arrest and apoptosis mediated by the p53 pathway(Abdel-Hamid and Morsy, 2010). These studies confirmed that the colloidal nanoparticles incorporating anticancer agents can improve drug action, distribution, biotransformation and clearance of anticancer agent, increasing the selectivity of drugs toward cancer cells and reducing their toxicity toward normal cell (Serpe, 2006, Villela-Martinez et al., 2017).

In the present study, the exposure to the ultrasonic waves (US) after treatment with 5-FU loaded Cs NPs, showed newly formed hepatocytes and other hepatocytes with large vesiculated nucleus, mild dilated central vein and few apoptotic cells around the central vein. This illustrated the effectiveness of ultrasonic exposure with loaded nanocarriers by increasing vascular permeability to accumulate the nanoparticles in the target organs and improve the injury caused by a toxic substances. Further study, in mice inoculated with a human colon cancer cell line to deliver fluorouracil encapsulated in stabilized micelles, showed a significant reduction in the tumor volume compared to the group that not received the US. The result explained that the US can improve the tumor blood supply and the drug content in tumor tissue increased remarkably (Grumezescu, 2016, Myhr and Moan, 2006)

The role of US was further evaluated by the result obtained from the biochemical analysis of ALT and MDA level, where exposing mice to the US caused a highly significant decrease in serum and hepatic ALT activity of group received 5-FU loaded Cs NPs when compared with free 5-FU group received US $(\mathrm{P}<$ $0.001 *)$. Also, US exposure triggered a significant decline in serum and hepatic ALT activity within 5-FU loaded Cs NPs group of $(\mathrm{P}=0.001 *)$. Exposing mice to the US caused a high significant decrease in hepatic MDA level of the group received 5-FU loaded Cs NPs when compared with free 5-FU group received US $(\mathrm{P}<$ $0.001 *)$. Also, US exposure triggered a significant decline in the hepatic MDA level within 5-FU loaded Cs NPs group $(\mathrm{P}=0.009 *)$.

The herein finding was supported by other researchers who stated that enhanced antitumor effect of liposomal doxorubicin was increased when combined with lowfrequency ultrasound, observed significant tumor growth delay indicated that the US can produce bioeffects, raise the tumor hemoperfusion, increase vascular permeability and increase drug content in tumor tissues as well as improve the accumulation of the nanoparticles in the tumor(Golombek et al., 2018, Wei et al., 2013). More enhanced correction in hepatic architecture was obtained after US exposure. The US can increase drug distribution in nucleic acid, as well as decrease the genotoxicity of the azo dye. The present work illustrated that the free form of 5-FU chemotherapy is less valuable than the one loaded on nanoparticles. The role of the ultrasound exposure was much more pronounced in the group received 5-FU loaded chitosan nanoparticles than the group received the free form of 5-FU. The present findings illustrated the achieved role of drug-loaded nanoparticles in enhancing drugs delivery when associated with Ultrasonic exposure.

\section{REFERENCES}

ABDEL-HAMID, N., FAWZY, M. \& ELMOSELHY, M. 2011. Evaluation of hepatoprotective and anticancer properties of aqueous olive leaf extract in chemically 
induced hepatocellular carcinoma in rats. $A m$ J Med Med Sci, 1, 15-22.

ABDEL-HAMID, N. M. \& MORSY, M. A. 2010. Novel biochemical pathways for 5Fluorouracil in managing experimental hepatocellular carcinoma in rats. Journal of Membrane Biology, 234, 29-34.

AYDIN, R. \& PULAT, M. 2012. 5-Fluorouracil encapsulated chitosan nanoparticles for $\mathrm{pH}$ stimulated drug delivery: evaluation of controlled release kinetics. Journal of Nanomaterials, 2012, 42.

BAKIRI, L. \& WAGNER, E. F. 2013. Mouse models for liver cancer. Mol Oncol, 7, 20623.

BALOGH, J., DAVID VICTOR III, E. H. A., BURROUGHS, S. G., BOKTOUR, M., SAHARIA, A., LI, X., GHOBRIAL, R. M. \& MONSOUR JR, H. P. 2016. Hepatocellular carcinoma: a review. Journal of hepatocellular carcinoma, 3, 41 .

BASU, A. 2018. DNA damage, mutagenesis and cancer. International journal of molecular sciences, $19,970$.

BHATTACHARJEE, N. \& KHUDA-BUKHSH, A. R. 2012. Two homeopathic remedies used intermittently provide additional protective effects against hepatotoxicity induced by carcinogens in mice. $J$ Acupunct Meridian Stud, 5, 166-75.

BHATTACHARJEE, N. \& KHUDA-BUKHSH, A. R. 2015. Homeopathic Remedies, Carcinosin200C and Natrum Sulphuricum200C, Used Intermittently Demonstrate Greater Ameliorative Response in Mice Intoxicated with Liver Carcinogens. Int. J. Life. Sci. Scienti. Res. eISSN, 2455, 1716.

BHATTACHARJEE, N., PATHAK, S. \& KHUDABUKHSH, A. R. 2009a. Amelioration of carcinogen-induced toxicity in mice by administration of a potentized homeopathic drug, Natrum Sulphuricum 200. EvidenceBased Complementary and Alternative Medicine, 6, 65-75.

BHATTACHARJEE, N., PATHAK, S. \& KHUDABUKHSH, A. R. 2009b. Amelioration of carcinogen-induced toxicity in mice by administration of a potentized homeopathic drug, natrum sulphuricum 200. Evid Based Complement Alternat Med, 6, 65-75.

BISWAS, S. J., BHATTACHARJEE, N. \& KHUDA-BUKHSH, A. R. 2008. Efficacy of a plant extract (Chelidonium majus L.) in combating induced hepatocarcinogenesis in mice. Food Chem Toxicol, 46, 1474-87.
BISWAS, S. J. \& KHUDA-BUKHSH, A. R. 2002. Effect of a homeopathic drug, Chelidonium, in amelioration of $\mathrm{p}-\mathrm{DAB}$ induced hepatocarcinogenesis in mice. $B M C$ Complement Altern Med, 2, 4.

BISWAS, S. J., PATHAK, S., BHATTACHARJEE, N., DAS, J. K. \& KHUDA-BUKHSH, A. R. 2005. Efficacy of the Potentized Homeopathic Drug, Carcinosin 200, Fed Alone and in Combination with Another Drug, Chelidonium 200, in Amelioration of p-Dimethylaminoazobenzene-Induced Hepatocarcinogenesis in Mice. Journal of Alternative \& Complementary Medicine, 11, 839-854.

CHEESEMAN, K. 1993. Mechanisms and effects of lipid peroxidation. Molecular Aspects of Medicine, 14, 191-197.

CHENG, M.-R., LI, Q., WAN, T., HE, B., HAN, J., CHEN, H.-X., YANG, F.-X., WANG, W., XU, H.-Z. \& YE, T. 2012. Galactosylated chitosan/5-fluorouracil nanoparticles inhibit mouse hepatic cancer growth and its side effects. World journal of gastroenterology: WJG, 18, 6076.

DE MINICIS, S., MARZIONI, M., BENEDETTI, A. \& SVEGLIATI-BARONI, G. 2013. New insights in hepatocellular carcinoma: from bench to bedside. Annals of translational medicine, 1.

DRURY, R. \& WALLINGTON, E. 1980. Carlton's histochemical technique. Oxford Univ. Press. Oxford.

EL-SERAG, H. B. 2002. Hepatocellular carcinoma: an epidemiologic view. Journal of clinical gastroenterology, 35, S72-S78.

FIGUEIREDO, M. \& ESENALIEV, R. 2012. PLGA Nanoparticles for Ultrasound-Mediated Gene Delivery to Solid Tumors. J Drug Deliv, 2012, 767839.

FILLER, R. B., ROBERTS, S. J. \& GIRARDI, M. 2007. Cutaneous two-stage chemical carcinogenesis. Cold Spring Harbor Protocols, 2007, pdb. prot 4837.

FOROUZANDEH, H., KALANTARI, H., SAKI, N., FORUOZANDEH, Z., AREFIAN, E., FARAHANI, A., HASSANI, G., BAZRAFSHAN, M. R. \& RASOULI, S. 2017. Role of oxidative stress in liver cancer. Clinical Cancer Investigation Journal, 6, 1.

GIRI, T. K., THAKUR, A., ALEXANDER, A., BADWAIK, H. \& TRIPATHI, D. K. 2012. Modified chitosan hydrogels as drug delivery and tissue engineering systems: 
present status and applications. Acta Pharmaceutica Sinica B, 2, 439-449.

GOLOMBEK, S. K., MAY, J.-N., THEEK, B., APPOLD, L., DRUDE, N., KIESSLING, F. \& LAMMERS, T. 2018. Tumor targeting via EPR: Strategies to enhance patient responses. Advanced drug delivery reviews.

GRUMEZESCU, A. 2016. Engineering of nanobiomaterials: applications of nanobiomaterials, William Andrew.

HANAHAN, D. \& WEINBERG, R. A. 2000. The hallmarks of cancer. cell, 100, 57-70.

HORSLEY, H., OWEN, J., CARUGO, D., MALONE-LEE, J., STRIDE, E. \& ROHN, J. L. 2019. Ultrasound-activated microbubbles as a novel intracellular drug delivery system for urinary tract infection. $J$ Control Release.

HWANG, I. T., CHUNG, Y. M., KIM, J. J., CHUNG, J. S., KIM, B. S., KIM, H. J., KIM, J. S. \& DO YOO, Y. 2007. Drug resistance to 5-FU linked to reactive oxygen species modulator 1. Biochemical and biophysical research communications, 359, 304-310.

KAPLOWITZ, N. 2000. Mechanisms of liver cell injury. Journal of hepatology, 32, 39-47.

KHAN, M. \& ALI, S. 2018. Appraisal of circulating biochemical markers and antioxidative activity in interferon intolerant $\mathrm{HCV}$ patients. MOJ Cell Sci Rep, 5, 64-70.

KULIK, L., HEIMBACH, J. K., ZAIEM, F., ALMASRI, J., PROKOP, L. J., WANG, Z., MURAD, M. H. \& MOHAMMED, K. 2018. Therapies for patients with hepatocellular carcinoma awaiting liver transplantation: A systematic review and meta-analysis. Hepatology, 67, 381-400.

KWO, P. Y., COHEN, S. M. \& LIM, J. K. 2017. ACG clinical guideline: evaluation of abnormal liver chemistries. The American journal of gastroenterology, 112, 18.

LARINA, I. V., EVERS, B. M., ASHITKOV, T. V., BARTELS, C., LARIN, K. V. \& ESENALIEV, R. O. 2005. Enhancement of drug delivery in tumors by using interaction of nanoparticles with ultrasound radiation. Technol Cancer Res Treat, 4, 217-26.

LI, S., TAN, H.-Y., WANG, N., ZHANG, Z.-J., LAO, L., WONG, C.-W. \& FENG, Y. 2015. The role of oxidative stress and antioxidants in liver diseases. International journal of molecular sciences, 16, 26087-26124.

LI, S., WANG, A., JIANG, W. \& GUAN, Z. 2008. Pharmacokinetic characteristics and anticancer effects of 5-fluorouracil loaded nanoparticles. BMC cancer, 8, 103.

LONGLEY, D. B., HARKIN, D. P. \& JOHNSTON, P. G. 2003. 5-Fluorouracil: mechanisms of action and clinical strategies. Nature Reviews Cancer, 3, 330.

MOHANRAJ, V. \& CHEN, Y. 2006. Nanoparticlesa review. Tropical journal of pharmaceutical research, 5, 561-573.

MYHR, G. \& MOAN, J. 2006. Synergistic and tumour selective effects of chemotherapy and ultrasound treatment. Cancer letters, 232, 206-213.

NAGARWAL, R. C., SINGH, P. N., KANT, S., MAITI, P. \& PANDIT, J. K. 2011. Chitosan nanoparticles of 5-fluorouracil for ophthalmic delivery: characterization, invitro and in-vivo study. Chemical and Pharmaceutical Bulletin, 59, 272-278.

NAGOEV, B., ABIDOV, M. \& IVANOVA, M. 2002. LPO and free-radical oxidation parameters in patients with acute viral hepatitis. Bulletin of experimental biology and medicine, 134, 557-558.

OTTOLENGHI, A. 1959. 2-Thiobarbituric acid (TBA) method. Arch Biochem Biophys, 77, 355.

PATHAK, S., CATANZARO, R., VASAN, D., MAROTTA, F., CHABRIA, Y., JOTHIMANI, G., VERMA, R. S., MURUGESAN, R., KHUDA-BUKHSH, A. R. \& BANERJEE, A. 2018. Benefits of aged garlic extract in modulating toxicity biomarkers against pdimethylaminoazobenzene and phenobarbital induced liver damage in Rattus norvegicus. Drug Chem Toxicol, 114.

PATHAK, S., ROY-KARMAKAR, S., BANERJEE, A., DUTTA, S. \& KHUDA-BUKHSH, A. 2009. Combinational homeopathic therapy reduces genotoxicity and cytotoxicity in mice fed carcinogens. Clin Exp Homeopath, 1,1 .

RAPOPORT, N., MARIN, A., MUNIRUZZAMAN, M. \& CHRISTENSEN, D. A. 2003. Controlled drug delivery to drug-sensitive and multidrug resistant cells: effects of pluronic micelles and ultrasound. ADVANCES IN CONTROLLED DRUG DELIVERY: SCIENCE, TECHNOLOGY, AND PRODUCTS, 846, 85-101.

REITMAN, S. \& FRANKEL, S. 1957. A colorimetric method for the determination of serum glutamic oxalacetic and glutamic 
pyruvic transaminases. American journal of clinical pathology, 28, 56-63.

SAAD, A. A., MOKHAMER, E.-H. M., MOHSEN, M. A. A. \& FADALY, G. A. 2014. Attenuation of carbon tetrachloride-induced hepatic fibrosis by glycine, vitamin $\mathrm{E}$, and vitamin C. J Exp Integr Med Jul-Sep, 4, 181.

SAHA, S. K., LEE, S. B., WON, J., CHOI, H. Y., KIM, K., YANG, G.-M., DAYEM, A. A. \& CHO, S.-G. 2017. Correlation between oxidative stress, nutrition, and cancer initiation. International journal of molecular sciences, 18, 1544.

SERPE, L. 2006. Conventional chemotherapeutic drug nanoparticles for cancer treatment. Nanomaterials for Cancer Therapy, 6, 1-30.

SHAH, A., MACDONALD, W., GOLDIE, J., GUDAUSKAS, G. \& BRISEBOIS, B. 1985. 5-FU infusion in advanced colorectal cancer: a comparison of three dose schedules. Cancer treatment reports, 69, 739-742.

SHI, X.-Y. \& FAN, X.-G. 2002. Advances in nanoparticle system for deliverying drugs across the biological barriers. JOURNALCHINA PHARMACEUTICAL UNIVERSITY, 33, 169-172.

TOMINAGA, T., YOSHIDA, Y., KOSAKI, G. \& KURIHARA, M. 1993. Effect of 5-Fluorouracil and UFT on Experimental Liver Metastasis Model of Colorectal Cancer Using Mouse Colon 26 Cells. Japanese journal of cancer research, 84, 783-786.

VILLELA-MARTINEZ, L. M., VELEZ-AYALA, A. K., DEL CARMEN LOPEZ-SANCHEZ, R., MARTINEZ-CARDONA, J. A. \& HERNANDEZ-HERNANDEZ, J. A. 2017.
Advantages of Drug Selective Distribution in Cancer Treatment: Brentuximab Vedotin. International Journal of Pharmacology, 13, 785-807.

WEI, H., HUANG, J., YANG, J., ZHANG, X., LIN, L., XUE, E. \& CHEN, Z. 2013. Ultrasound exposure improves the targeted therapy effects of galactosylated docetaxel nanoparticles on hepatocellular carcinoma xenografts. PloS one, 8, e58133.

WORETA, T. A. \& ALQAHTANI, S. A. 2014. Evaluation of abnormal liver tests. Medical Clinics, 98, 1-16.

XIN, B., CUI, Y., WANG, Y., WANG, L., YIN, J., ZHANG, L., PANG, H., ZHANG, H. \& WANG, R. A. 2017. Combined use of alcohol in conventional chemical-induced mouse liver cancer model improves the simulation of clinical characteristics of human hepatocellular carcinoma. Oncology letters, 14, 4722-4728.

YAN, C., CHEN, D., GU, J. \& QIN, J. 2006. Nanoparticles of 5-fluorouracil (5-FU) loaded N-succinyl-chitosan (Suc-Chi) for cancer chemotherapy: preparation, characterization - in-vitro drug release and anti-tumour activity. Journal of pharmacy and pharmacology, 58, 1177-1181.

ZOLOCHEVSKA, O., XIA, X., WILLIAMS, B. J., RAMSAY, A., LI, S. \& FIGUEIREDO, M. L. 2011. Sonoporation delivery of interleukin-27 gene therapy efficiently reduces prostate tumor cell growth in vivo. Hum Gene Ther, 22, 1537-50. 